\title{
Utility of Cardiac CT for Preoperative Evaluation of Mitral Regurgitation: Morphological Evaluation of Mitral Valve and Prediction of Valve Replacement
}

\author{
Young Joo Suh, MD, PhD ${ }^{1 *}$, Sak Lee, MD, PhD ${ }^{2 *}$, Byung-Chul Chang, MD, PhD ${ }^{3}$, \\ Chi Young Shim, MD, PhD ${ }^{4}$, Geu-Ru Hong, MD, PhD ${ }^{4}$, Byoung Wook Choi, MD, PhD ${ }^{1}$, \\ Young Jin Kim, MD, $\mathrm{PhD}^{1}$ \\ ${ }^{1}$ Department of Radiology, Severance Hospital, Yonsei University College of Medicine, Seoul, Korea; ${ }^{2}$ Department of Cardiovascular Surgery, \\ Severance Cardiovascular Hospital, Yonsei University College of Medicine, Seoul, Korea; ${ }^{3}$ Department of Thoracic and Cardiovascular Surgery, CHA \\ Bundang Medical Center, CHA University, Seongnam, Korea; ${ }^{4}$ Department of Cardiology, Severance Cardiovascular Hospital, Yonsei University \\ College of Medicine, Seoul, Korea
}

Objective: We aimed to investigate the diagnostic accuracy of cardiac computed tomography (CT) for the detection of mitral valve (MV) prolapse in mitral regurgitation (MR) with surgical findings as the standard reference, and to assess the predictability of MV replacement based on morphologic CT findings.

Materials and Methods: A total of 156 patients who had undergone preoperative cardiac CT and subsequently received MV surgery due to severe MR were retrospectively enrolled. Non-repairable MV was defined when at least one of the following conditions was met: 1) anterior leaflet prolapse, 2) bi-leaflet prolapse, or 3) valve morphology (leaflet thickening, calcification, or mitral annular calcification [MAC]). Diagnostic performance of CT for the detection of the prolapsed segment was assessed with surgical findings as the standard reference. Logistic regression analysis was performed to evaluate the value of CT findings to predict actual valve replacement.

Results: During surgery, MV prolapse was identified in $72.1 \%$. The sensitivity, specificity, and diagnostic accuracy for the detection of MV prolapse were $99.1 \%, 81.4 \%$, and $94.2 \%$, respectively, per patient. One-hundred eighteen patients $(75.6 \%)$ underwent MV repair and the remaining 38 patients received MV replacement. Bi-leaflet prolapse and valve morphology were independent predictors of valve replacement after adjusting for clinical variables (adjusted odds ratio, [OR] 8.63 for bi-leaflet prolapse; OR, 4.14 for leaflet thickening; and OR, 5.37 for leaflet calcium score $>5.6 ; p<0.05$ ).

Conclusion: Cardiac CT can have high diagnostic performance for detecting the prolapsed segment of the MV and predictability of valve replacement before surgery. Bi-leaflet prolapse and valve morphology, such as leaflet thickening, or calcification or $M A C$, are the most important predictors of valve replacement.

Keywords: Mitral regurgitation; Mitral valve prolapse; Computed tomography; Mitral valve surgery; Preoperative planning

\section{INTRODUCTION}

Mitral valve (MV) repair is widely regarded as the procedure of choice for significant non-rheumatic mitral regurgitation (MR) requiring surgery. Operative risks and outcomes are better for patients undergoing MV repair versus MV replacement in patients with MR who have valve morphology suitable for repair (1-3). Although the rate of MV repair over MV replacement has been increasing, a number of patients with primary MR will still undergo

Received June 12, 2018; accepted after revision October 5, 2018.

*These authors contributed equally to this work.

Corresponding author: Young Jin Kim, MD, PhD, Department of Radiology, Severance Hospital, Yonsei University College of Medicine, 50-1 Yonsei-ro, Seodaemun-gu, Seoul 03722, Korea.

- Tel: (822) 2228-7400 • Fax: (822) 393-3035• E-mail: dryj@yuhs.ac

This is an Open Access article distributed under the terms of the Creative Commons Attribution Non-Commercial License (https:// creativecommons.org/licenses/by-nc/4.0) which permits unrestricted non-commercial use, distribution, and reproduction in any medium, provided the original work is properly cited. 
MV replacement (4). The feasibility of MV repair depends not only on the pathology or morphology, but also on the experience of the surgeon and/or the valve team, and sometimes it is very challenging $(5,6)$. Generally, the success rate of MR with isolated posterior leaflet prolapse reaches almost $100 \%$; in contrast, repair of the anterior leaflet or bi-leaflet prolapse is technically more demanding and associated with worse outcomes (7-11). Moreover, leaflet restriction with thickening and/or calcification, which can be frequently seen in rheumatic heart disease, is considered less suitable for repair (12). In addition, severe mitral annular calcification (MAC) is associated with increased complications following MV surgery and intraoperative conversion from MV repair to replacement (13-16).

Appropriate selection of a repairable valve is critical to preoperative planning because of recurrent $M R$, which is the most common cause of MV repair failure and usually develops after the repair of a non-repairable valve in the initial surgery $(11,17,18)$. Recurrent MR is related to adverse outcomes such as reoperation, heart failure, and cardiac death (19). Moreover, conversion from MV repair to replacement in the surgical field may result in a longer operation time (20).

Transthoracic echocardiography (TTE) can provide information about the MV, not only in the assessment of the mechanism and severity of MR, but also in quantifying the hemodynamic consequences of MR as determined by left ventricular (LV) size and function, left atrial size, and pulmonary artery pressure. TTE has been reported to have high diagnostic performance for detecting the prolapsed segment of the MV, which is a common finding in degenerative MR (21). Moreover, TTE can provide information about valve morphology such as thickening or calcification of a leaflet or the subvalvular apparatus. However, TTE may have limited value in patients with a poor echo window. Cardiac computed tomography (CT) has the advantage of excellent spatial resolution and recently received attention regarding its comprehensive anatomic evaluation of the MV complex and morphological abnormalities (22). A few previous studies have investigated the utility of cardiac CT in MV disease, most of which have focused on the diagnostic performance of CT for the detection of MV prolapse (23-26). CT can also be used for the geometric assessment of the MV leaflet, annulus, and LV remodeling to help determine the mechanism of functional MR (27). Therefore, we hypothesized that cardiac CT can help evaluate valve morphology and predict MV replacement in patients with severe MR.

We aimed to investigate the diagnostic accuracy of cardiac CT for the detection of MV prolapse in severe MR with surgical findings as the standard reference and to assess the ability of $\mathrm{CT}$ findings regarding morphologic evaluation to predict MV replacement.

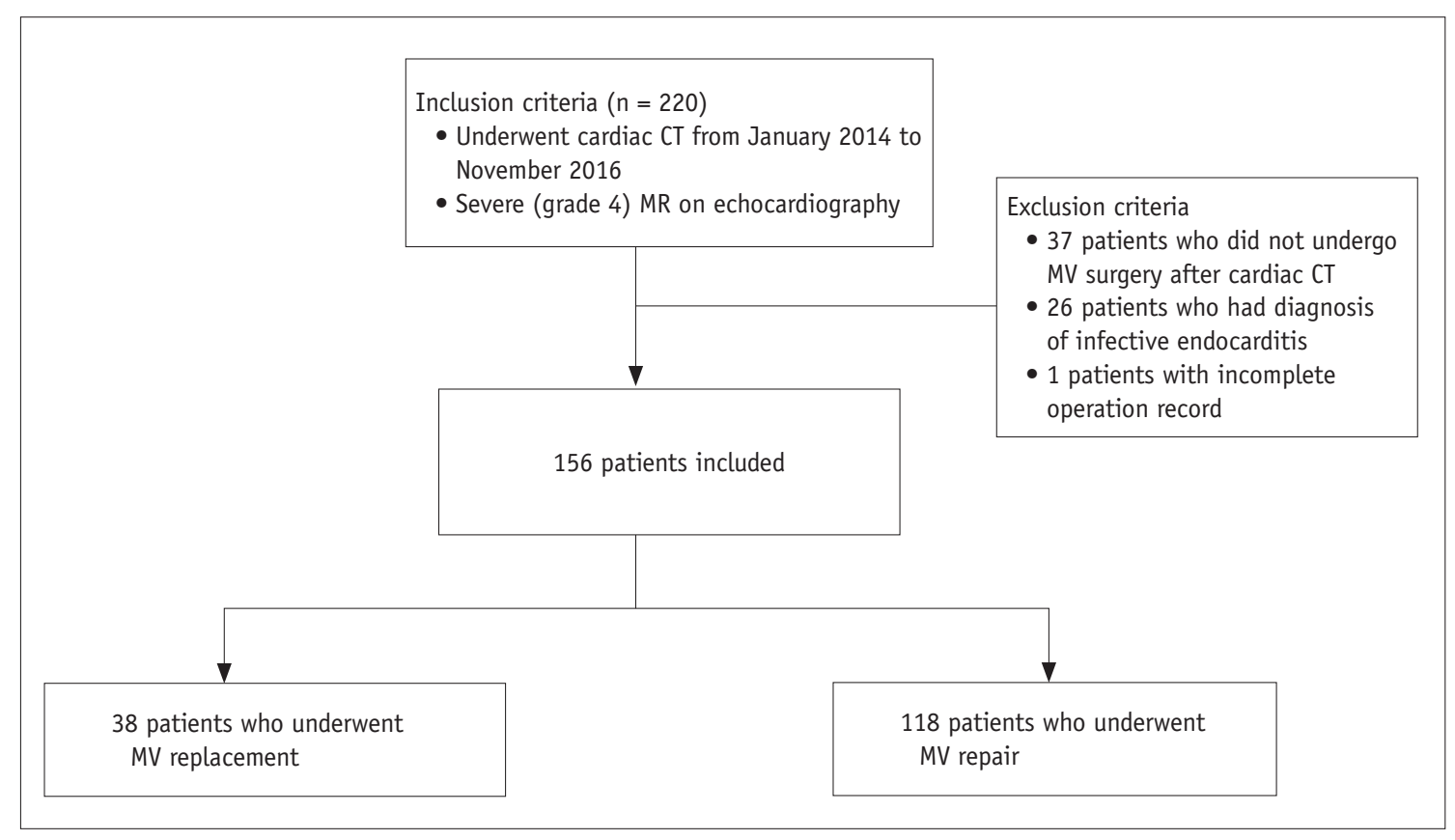

Fig. 1. Flowchart of study population. $C T=$ computed tomography, $M R=$ mitral regurgitation, $M V=$ mitral valve 


\section{MATERIALS AND METHODS}

\section{Patients}

The Institutional Review Board of our institution approved this retrospective study and informed consent was waived. We enrolled 220 consecutive patients who were planned to receive MV surgery due to severe (grade 4) MR without significant mitral stenosis on echocardiography and were referred for cardiac $\mathrm{CT}$ for preoperative evaluation of the coronary artery and cardiac structures from January 2014 to November 2016 (Fig. 1). Among these patients, we excluded 37 patients who did not undergo MV surgery (MV repair or replacement) after cardiac CT scan, 26 patients with infective endocarditis, and one patient with an incomplete operation record. We excluded patients with infective endocarditis because the criteria for the assessment of a nonrepairable valve (described in "Findings of a non-repairable valve") could not be applied the same as in other etiologies, in the terms that extensive destruction of the valvular and subvalvular apparatus and rupture of the chordae tendineae would make repair impossible in patients with infective endocarditis (28). Finally, a total of 156 patients who underwent MV surgery after a cardiac CT scan due to severe MR from non-infective endocarditis were included. Demographic data and information regarding the MV surgery were collected from the electronic medical records.
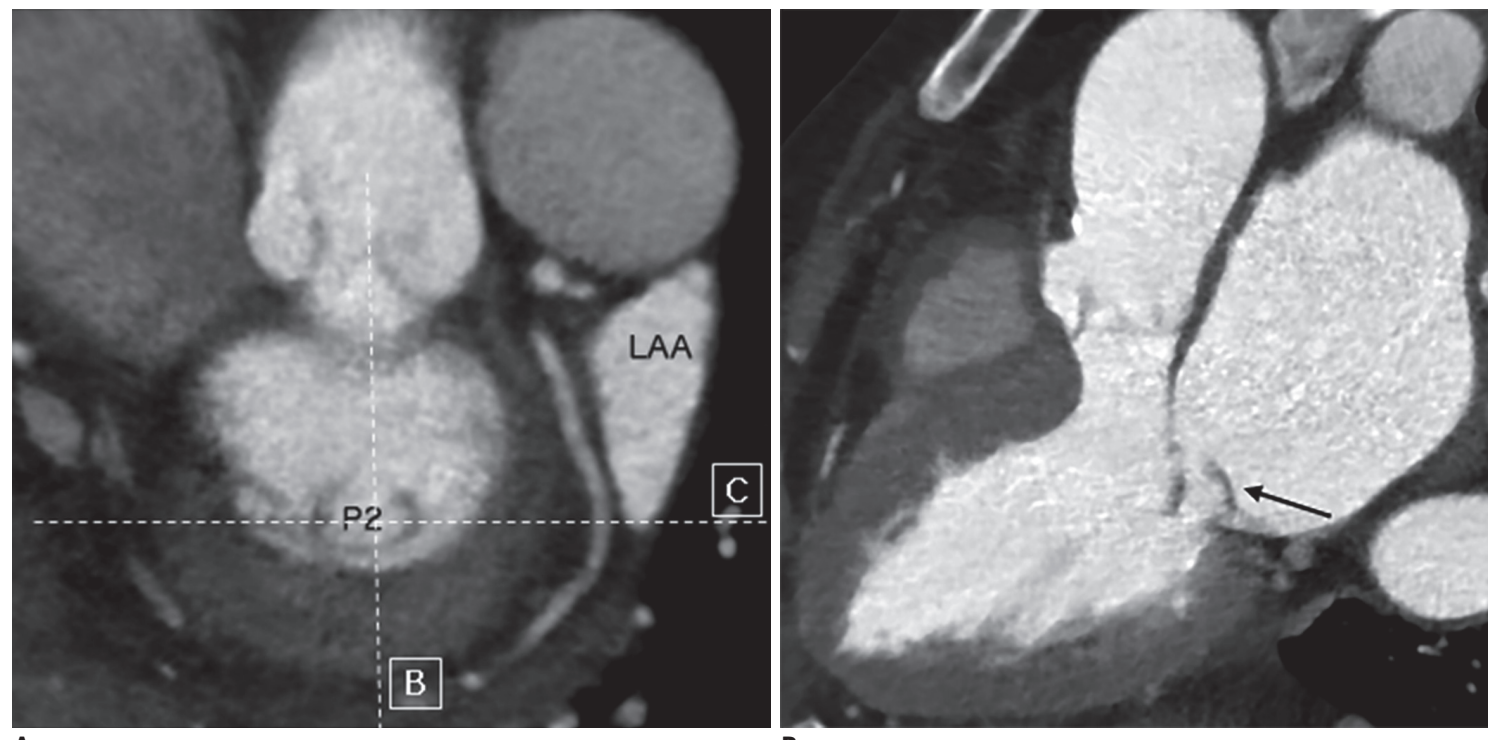

A B
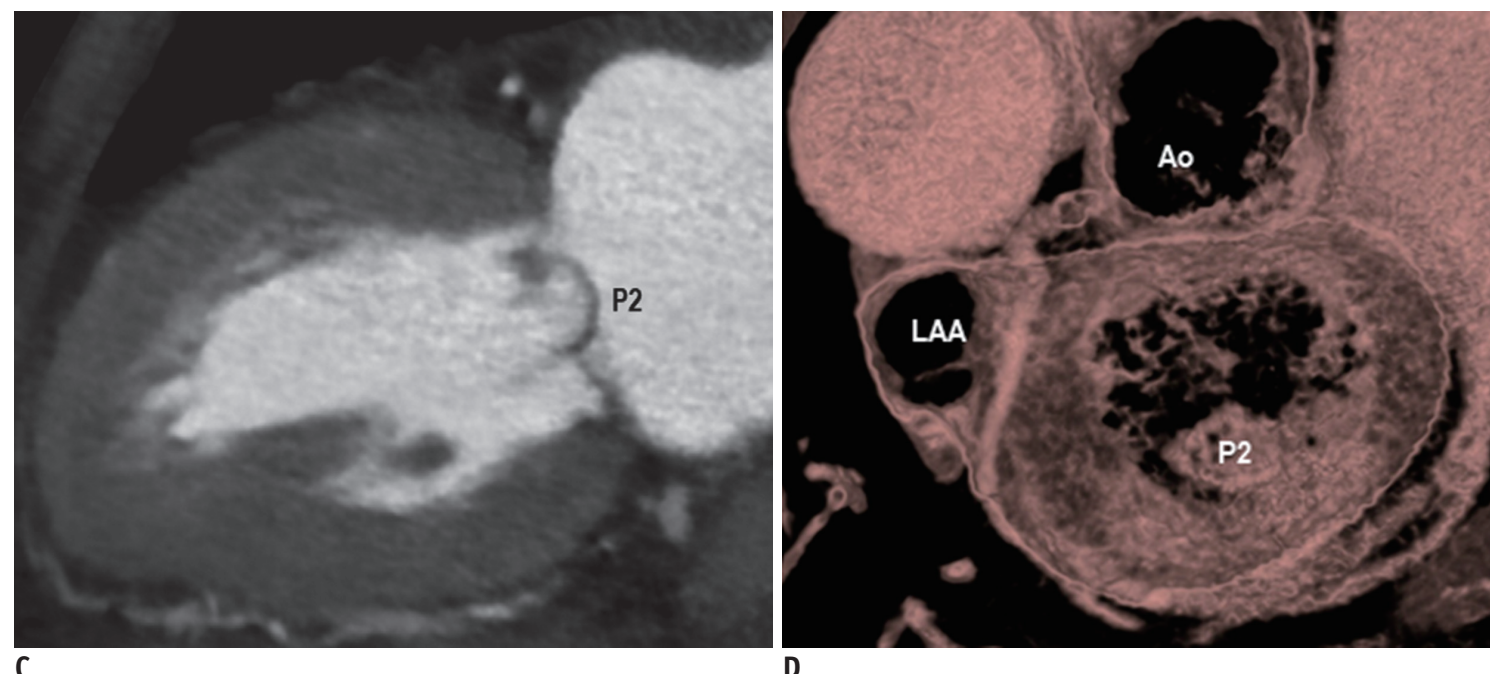

Fig. 2. CT images of repairable MV in 70-year-old female patient with degenerative MR.

Short-axis CT image of MV (A), CT images parallel to (B) and perpendicular to intercommissural axis (C), and three-dimensional volume-rendered image from surgeon's view (D), showing prolapse of P2 scallop (arrow) without leaflet thickening or calcification, or mitral annular calcification. Patient underwent MV repair with ring annuloplasty. $\mathrm{Ao}=$ aorta, $\mathrm{LAA}=$ left atrial appendage 


\section{CT Image Acquisition and Reconstruction}

All cardiac CT scans were performed with a second generation dual-source CT scanner (SOMATOM Definition Flash, Siemens Healthineers, Forchheim, Germany). Before the contrast administration, non-enhanced calcium scoring images were acquired, and cardiac CT angiography was performed using the retrospective electrocardiogram (ECG)-gated data acquisition mode. Details of acquisition reconstruction are described in the Supplementary Materials (in the online-only Data Supplement).

\section{CT Image Analysis}

All CT analyses were performed by one radiologist with 6 years of experience with cardiac CT who was blinded to the clinical information. Assessment of the MV consisted of the evaluation of MV prolapse and leaflet morphology (Figs. 2-4). The presence of MV prolapse and leaflet thickening was assessed using $\mathrm{CT}$ angiography with multiplanar reformatted images in a short-axis image of the MV annulus, a long-axis view of the LV, and a four-chamber view. MV prolapse was defined as leaflet displacement greater than $2 \mathrm{~mm}$ below the annulus plane (Fig. 2), and assessed per patient, leaflet (anterior or posterior), and scallop (24). Per scallop evaluation of the prolapsed segment of the MV was assessed using the Carpentier classification (29). Bi-leaflet prolapse was defined as the presence of both anterior and posterior leaflet prolapse. For the evaluation of valve leaflet thickening, the maximal thickness of the MV leaflet was measured, and considered as thickened when the leaflet thickness was over $2 \mathrm{~mm}$ (24). Presence of MV leaflet calcification or MAC was assessed using the non-enhanced calcium scoring scan and CT angiography. For qualitative analysis, the presence of calcification was visually assessed. Quantitative assessment of MV leaflet calcification and MAC was performed by calculating the calcium score of the leaflet and mitral annulus separately using the Agatston scoring method (30).

\section{Findings of a Non-Repairable Valve}

We established findings of a non-repairable valve (requiring valve replacement) as those meeting the following conditions: 1) valve with anterior leaflet prolapse, 2) valve with bi-leaflet prolapse, or 3 ) valve with nonrepairable morphology $(24,28,31)$. Non-repairable valve morphology was considered when at least one of following findings was present: 1) leaflet thickening (> $2 \mathrm{~mm}), 2)$ MV leaflet calcification, or 3) MAC. Presence of these findings was assessed both on the preoperative cardiac CT and TTE.

\section{Surgical Findings}

From the surgical records, the type of surgery (either MV replacement or repair) was investigated. The records for the prolapsed segments and morphology assessed during surgery were also obtained. Generally, intraoperative transesophageal echocardiography (TEE) was performed for the identification of the prolapsed MV segments and other abnormalities in the subvalvular structures of the MV. Moreover, the presence of MV prolapse and evaluation of valve morphology were confirmed by inspection during surgery. The surgical technique used for the correction of severe MR was also recorded, such as MV replacement, ring annuloplasty, leaflet resection, or chordae surgery

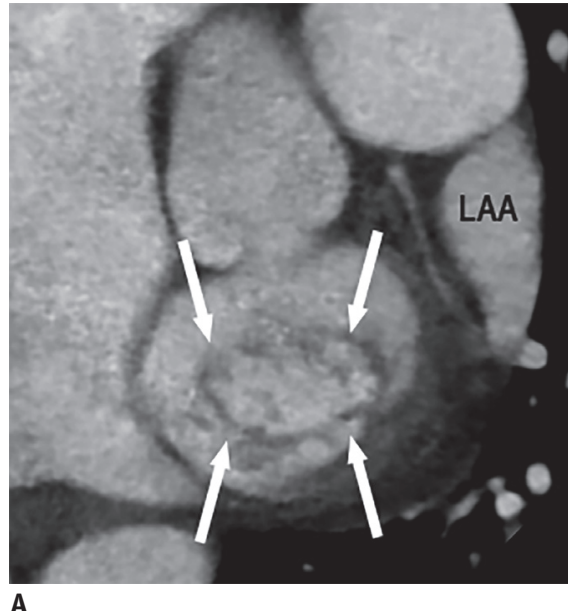

A

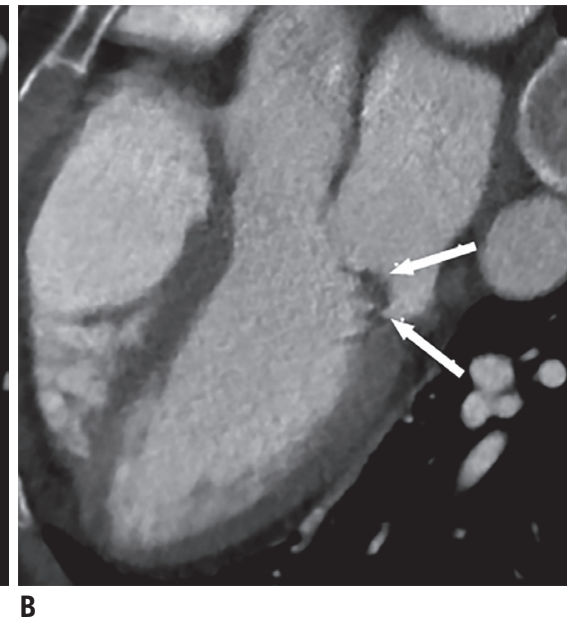

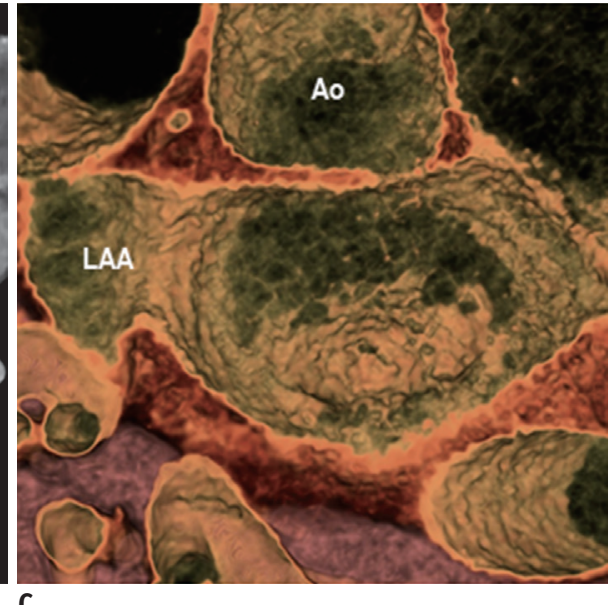

C

Fig. 3. CT images of non-repairable MV in 46-year-old female patient showing bi-leaflet prolapse and leaflet thickening.

A, B. CT images of MV show bi-leaflet prolapse (arrows) and leaflet thickening. C. Three-dimensional volume-rendered image from surgeon's view shows prolapse of both leaflets. Patient underwent MV replacement with tissue valve. 


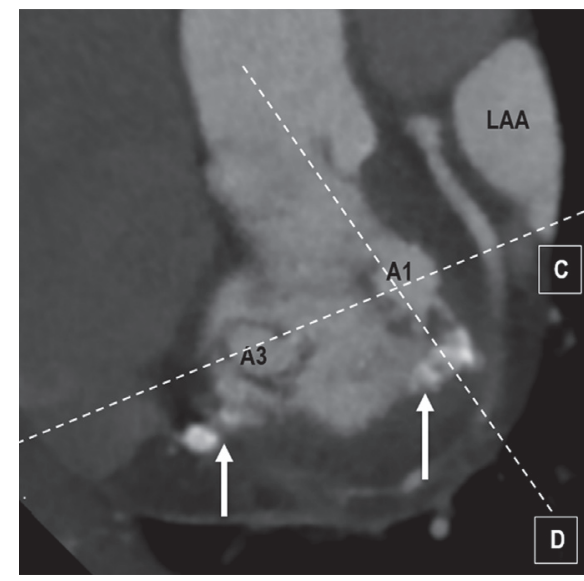

A

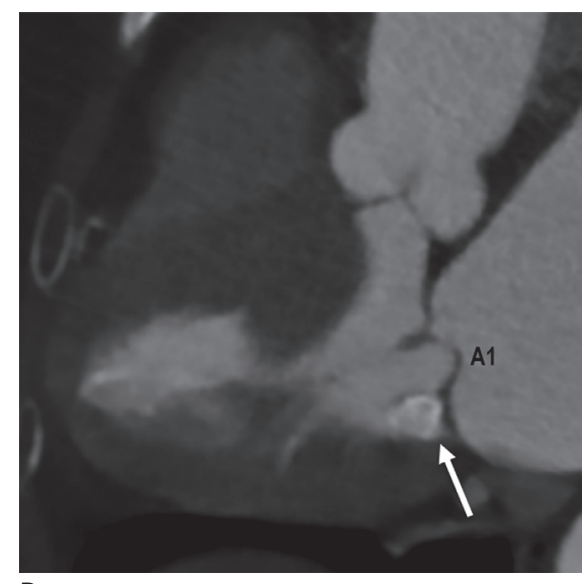

D

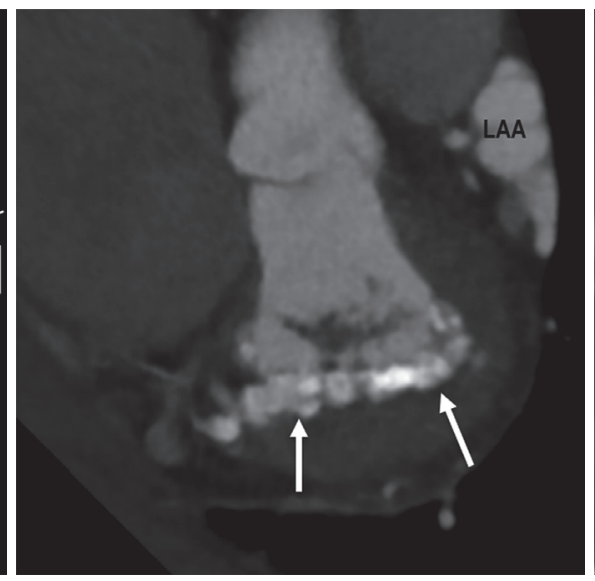

B

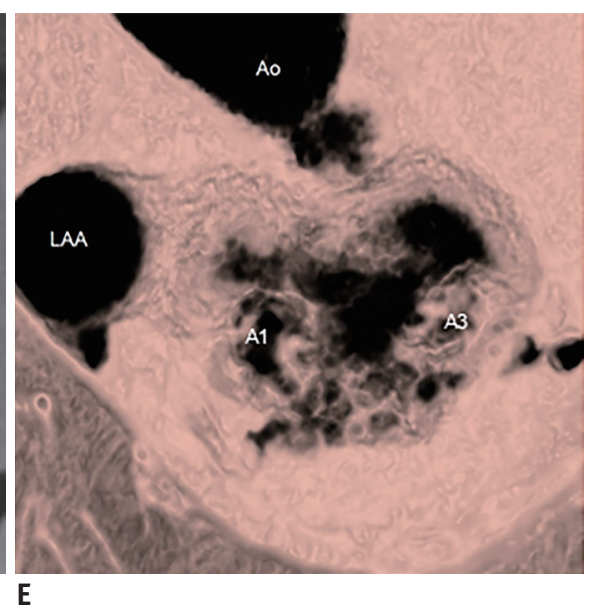

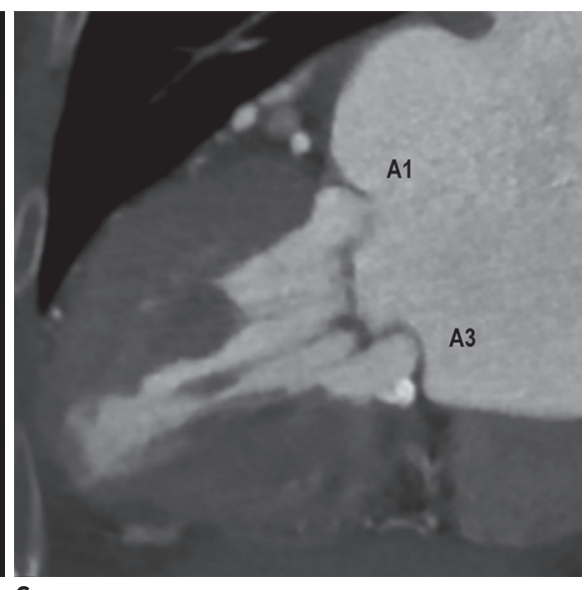

C

Fig. 4. CT images of non-repairable MV in 77-year-old female patient with degenerative MR, showing anterior leaflet prolapse, MV leaflet thickening and calcification, and mitral annular calcification.

(A, B) Short-axis CT images of MV show severe mitral annular calcification (arrows) and leaflet thickening. CT images parallel to (C) and perpendicular to intercommissural axis (D), and three-dimensional volume-rendered image of surgeon's view (E) shows prolapse of A1 and A3 scallops, thickening of MV leaflets, and leaflet calcification (arrow). Patient underwent MV replacement with tissue valve.

(neochordae formation or chordae shortening).

\section{TTE and TEE}

TTE was performed before and after MV surgery as part of routine clinical practice using standard methods. LV assessment employed the parasternal long-axis view with two-dimensional direct measurements or guided M-mode at end-diastole and end-systole and measurement of the LV ejection fraction $(32,33)$. MR severity was assessed on a scale from 1 to 4 using Doppler echocardiography for a comprehensive MR assessment on the basis of specific and supporting signs of MR quantitation (34). The presence of anterior or bi-leaflet prolapse, and findings regarding non-repairable valve morphology (leaflet thickening or calcification or MAC) were assessed on preoperative TTE. In some cases, TEE was performed after TTE examination, especially when TTE provided non-diagnostic information about the severity of MR, mechanism of MR, and/or status of LV function. Postoperative follow-up echocardiographic examinations were performed after discharge in all but sixteen patients. The first Doppler echocardiographic study demonstrating moderate or severe MR was considered “recurrent MR" (19).

\section{Statistical Analysis}

Statistical analyses were performed using computerized statistics programs (MedCalc Statistical Software version 18.9, MedCalc Software bvba, 0stend, Belgium; R, version 3.5.1., R Foundation for Statistical Computing, Vienna, Austria). Normally distributed data were identified using the Shapiro-Wilk W test. Continuous variables are presented as the mean \pm standard deviation and were compared using 
the independent $t$ test for normally distributed data or Mann-Whitney U test for non-normally distributed data. Comparison of the distribution of the prolapsed segment and valve morphology according to the etiology of valvular heart disease was performed using the chi-square test or Fisher's exact test. The diagnostic performance of cardiac CT for the detection of the prolapsed segment of the MV was assessed per patient, leaflet, and segment. Intraobserver variability for CT findings of valve morphology was assessed using kappa statistics. Logistic regression analysis was performed to explore the value of each finding of nonrepairable MV to predict valve replacement (Supplementary Materials in the online-only Data Supplement). Otherwise, $p$ values $<0.05$ were considered statistically significant.

\section{RESULTS}

\section{Patients}

The clinical characteristics of the study population are summarized in Table 1 . Among the 156 patients, 18 patients $(11.5 \%)$ had rheumatic MR and the remaining 138 patients

Table 1. Patient Characteristics and Information about MV Surgery

\begin{tabular}{lc}
\hline \multicolumn{1}{c}{ Characteristics } & Data $(\mathrm{n}=156)$ \\
\hline Male sex & $77(49.4)$ \\
Age $^{*}$ & $1.65(1.53-1.83)$ \\
${\text { Body surface area }\left(\mathrm{m}^{2}\right)^{*}}^{\text {Etiology of MV disease }^{\dagger}}$ & $129(82.7)$ \\
\hline Degenerative & $18(11.5)$ \\
\hline Rheumatic & $4(2.5)$ \\
\hline Congenital & $3(3.2)$ \\
\hline Secondary & $38(24.4)$ \\
Information about MV surgery & $118(75.6)$ \\
\hline MV replacement & $118(100)$ \\
\hline MV repair & \\
\hline Ring annuloplasty & $27(22.9)$ \\
Leaflet resection & $4(3.4)$ \\
\hline Triangular resection & $13(11.0)$ \\
\hline Quadriangular resection & \\
\hline Wedge resection & $42(35.6)$ \\
Chordae surgery & $3(2.5)$ \\
\hline Neochordae formation & $11(9.3)$ \\
\hline Chordae shortening & $4(3.4)$ \\
\hline Commissuroplasty & \\
\hline Miscellaneous & \\
\hline Except where indicated & \\
\hline
\end{tabular}

Except where indicated, data are number of patients, with percentages in parentheses. *Data are medians, with 25th-75th percentile range in parentheses, ${ }^{\dagger}$ Suggested based on preoperative study results. $\mathrm{MV}=$ mitral valve
(88.5\%) had non-rheumatic MR. One hundred and eighteen patients $(75.6 \%)$ underwent MV repair during corrective surgery for MR and the remaining 38 patients (24.4\%) underwent MV replacement. After excluding 18 patients with a rheumatic etiology, 115 patients (83.3\%) underwent MR repair and 23 patients $(16.7 \%)$ underwent MR replacement.

\section{CT Image Analysis}

For the analysis of the detection of the prolapsed segment, two patients with congenital MR were excluded because segmentation of the MV scallop was difficult. In the remaining 154 patients, the diagnostic performance of cardiac CT for the detection of MV prolapse was as follows: sensitivity, $99.1 \%$; specificity, $81.4 \%$; positive predictive value, $93.2 \%$; negative predictive value, $97.2 \%$; and accuracy, $94.2 \%$ per patient (Table 2). Posterior leaflet prolapse was the most common location (60.5\%) in degenerative disease $(p<0.001)$ (Table 3). Anterior leaflet prolapse was commonly seen in degenerative MR $(p=0.030)$. Leaflet thickening was most commonly seen in rheumatic MR $(83.3 \%)$, followed by congenital $(75 \%)$ and degenerative etiologies $(53.1 \%, p=0.028)$. Leaflet calcification was seen in $50 \%$ of cases of rheumatic and congenital MR, more frequently than in degenerative MR ( $p$ $<0.001)$, whereas MAC was seen in both rheumatic $(22.2 \%)$ and degenerative MR $(18.6 \%)$ at similar frequencies ( $p$ $=0.788)$. Intra-observer agreement ranged from good to excellent \{kappa (95\% confidence interval [CI]); 0.725 (0.616-0.834) for leaflet thickening, 0.820 (0.681-0.960) for leaflet calcification, and 0.911 (0.824-0.997) for MAC\}.

\section{Findings of Non-Repairable Valve and Prediction of Actual Valve Replacement}

Non-repairable MV was considered present in 117 cases based on CT image analysis and 88 cases based on TTE results (Table 3 ). Analysis by etiology found that rheumatic heart disease had a significantly higher proportion of non-repairable valves on CT than other etiologies, along with a subsequent higher percentage of patients receiving valve replacement. CT and TTE findings for the assessment of a non-repairable valve showed excellent agreement for anterior leaflet prolapse, moderate agreement for bi-leaflet prolapse, and poor agreement for valve morphology (Supplementary Table 1 in the online-only Data Supplement). For the diagnosis of each finding of non-repairable valve, CT tended to show higher sensitivity, specificity, and diagnostic accuracy for the detection of 
Table 2. Diagnostic Performance of Cardiac CT for Detection of MV Prolapse with Surgical Findings as Standard Reference

\begin{tabular}{|c|c|c|c|c|c|c|c|c|c|}
\hline & $\begin{array}{c}\text { True- } \\
\text { Positive }\end{array}$ & $\begin{array}{c}\text { True- } \\
\text { Negative }\end{array}$ & $\begin{array}{l}\text { False- } \\
\text { Positive }\end{array}$ & $\begin{array}{l}\text { False- } \\
\text { Negative }\end{array}$ & Sensitivity & Specificity & $\begin{array}{c}\text { Positive } \\
\text { Predictive } \\
\text { Value }\end{array}$ & $\begin{array}{c}\text { Negative } \\
\text { Predictive } \\
\text { Value }\end{array}$ & $\begin{array}{c}\text { Diagnostic } \\
\text { Accuracy }\end{array}$ \\
\hline \multicolumn{10}{|l|}{$\mathrm{CT}(\mathrm{n}=154)$} \\
\hline Patient & 110 & 35 & 8 & 1 & $\begin{array}{c}110 / 111 \\
(99.1)\end{array}$ & $\begin{array}{l}35 / 43 \\
(81.4)\end{array}$ & $\begin{array}{c}110 / 118 \\
(93.2)\end{array}$ & $\begin{array}{l}35 / 36 \\
(97.2)\end{array}$ & $\begin{array}{c}136 / 154 \\
(94.2)\end{array}$ \\
\hline Anterior leaflet & 47 & 99 & 4 & 4 & $\begin{array}{l}47 / 51 \\
(92.2)\end{array}$ & $\begin{array}{c}99 / 103 \\
(96.1)\end{array}$ & $\begin{array}{l}47 / 51 \\
(92.2)\end{array}$ & $\begin{array}{c}99 / 103 \\
(96.1)\end{array}$ & $\begin{array}{c}146 / 154 \\
(94.8)\end{array}$ \\
\hline $\mathrm{A} 1$ & 13 & 130 & 6 & 5 & $\begin{array}{l}13 / 18 \\
(72.2)\end{array}$ & $\begin{array}{c}130 / 136 \\
(95.6)\end{array}$ & $\begin{array}{l}13 / 19 \\
(68.4)\end{array}$ & $\begin{array}{c}130 / 135 \\
(96.3)\end{array}$ & $\begin{array}{c}143 / 154 \\
(92.9)\end{array}$ \\
\hline A2 & 18 & 122 & 4 & 10 & $\begin{array}{l}18 / 28 \\
(64.3)\end{array}$ & $\begin{array}{c}122 / 126 \\
(96.8)\end{array}$ & $\begin{array}{l}18 / 22 \\
(81.8)\end{array}$ & $\begin{array}{c}122 / 132 \\
(92.4)\end{array}$ & $\begin{array}{c}140 / 154 \\
(90.9)\end{array}$ \\
\hline A3 & 22 & 121 & 5 & 6 & $\begin{array}{l}22 / 28 \\
(78.6)\end{array}$ & $\begin{array}{c}121 / 126 \\
(96.0)\end{array}$ & $\begin{array}{l}22 / 27 \\
(81.5)\end{array}$ & $\begin{array}{c}121 / 127 \\
(95.3)\end{array}$ & $\begin{array}{c}143 / 154 \\
(92.9)\end{array}$ \\
\hline Posterior leaflet & 73 & 74 & 7 & 0 & $\begin{array}{l}73 / 73 \\
(100)\end{array}$ & $\begin{array}{l}74 / 81 \\
(91.4)\end{array}$ & $\begin{array}{l}73 / 80 \\
(91.3)\end{array}$ & $\begin{array}{c}74 / 74 \\
(100.0)\end{array}$ & $\begin{array}{c}147 / 154 \\
(95.5)\end{array}$ \\
\hline P1 & 14 & 124 & 14 & 2 & $\begin{array}{l}14 / 16 \\
(87.5)\end{array}$ & $\begin{array}{c}124 / 136 \\
(89.9)\end{array}$ & $\begin{array}{l}14 / 28 \\
(50.0)\end{array}$ & $\begin{array}{c}124 / 126 \\
(98.4)\end{array}$ & $\begin{array}{c}138 / 154 \\
(89.6)\end{array}$ \\
\hline P2 & 31 & 112 & 6 & 5 & $\begin{array}{l}31 / 36 \\
(86.1)\end{array}$ & $\begin{array}{c}112 / 118 \\
(94.9)\end{array}$ & $\begin{array}{l}31 / 37 \\
(83.8)\end{array}$ & $\begin{array}{c}112 / 117 \\
(95.7)\end{array}$ & $\begin{array}{c}143 / 154 \\
(92.9)\end{array}$ \\
\hline P3 & 37 & 102 & 14 & 1 & $\begin{array}{l}37 / 38 \\
(97.4)\end{array}$ & $\begin{array}{c}102 / 116 \\
(87.9)\end{array}$ & $\begin{array}{l}37 / 51 \\
(72.5)\end{array}$ & $\begin{array}{c}102 / 103 \\
(99.0)\end{array}$ & $\begin{array}{c}139 / 154 \\
(90.3)\end{array}$ \\
\hline Per leaflet & 120 & 173 & 11 & 4 & $\begin{array}{c}120 / 1124 \\
(96.8)\end{array}$ & $\begin{array}{c}173 / 184 \\
(94.0)\end{array}$ & $\begin{array}{c}120 / 131 \\
(91.6)\end{array}$ & $\begin{array}{c}173 / 177 \\
(97.7)\end{array}$ & $\begin{array}{c}293 / 308 \\
(95.1)\end{array}$ \\
\hline Per segment & 135 & 711 & 49 & 29 & $\begin{array}{c}135 / 164 \\
(82.3)\end{array}$ & $\begin{array}{c}711 / 760 \\
(93.6)\end{array}$ & $\begin{array}{c}135 / 184 \\
(73.4)\end{array}$ & $\begin{array}{c}711 / 740 \\
(96.1)\end{array}$ & $\begin{array}{c}846 / 924 \\
(91.6)\end{array}$ \\
\hline $\begin{array}{l}\text { Single scallop } \\
\text { involvement }\end{array}$ & 67 & 575 & 43 & 5 & $\begin{array}{l}67 / 72 \\
(93.1)\end{array}$ & $\begin{array}{c}575 / 618 \\
(93.0)\end{array}$ & $\begin{array}{c}67 / 110 \\
(60.9)\end{array}$ & $\begin{array}{c}575 / 580 \\
(99.1)\end{array}$ & $\begin{array}{c}642 / 690 \\
(93.0)\end{array}$ \\
\hline $\begin{array}{l}\text { Multi-scallop } \\
\text { involvement }\end{array}$ & 68 & 378 & 22 & 24 & $\begin{array}{l}68 / 92 \\
(73.9)\end{array}$ & $\begin{array}{c}378 / 400 \\
(94.5)\end{array}$ & $\begin{array}{l}68 / 90 \\
(75.6)\end{array}$ & $\begin{array}{c}378 / 402 \\
(94.0)\end{array}$ & $\begin{array}{c}446 / 492 \\
(90.6)\end{array}$ \\
\hline
\end{tabular}

Data are number of patients, with percentages in parentheses. CT = computed tomography

Table 3. Distribution of Location of MV Prolapse and Valve Morphology According to Etiology

\begin{tabular}{|c|c|c|c|c|c|c|}
\hline & Entire Group & Degenerative & Rheumatic & Congenital & Secondary & $P$ \\
\hline \multicolumn{7}{|l|}{ CT findings } \\
\hline Anterior leaflet prolapse* & $51 / 154(33.1)$ & 49/129 (38.0) & $1 / 18(5.6)$ & $0 / 2(0)$ & $1 / 5(20)$ & 0.030 \\
\hline Posterior leaflet prolapse* & $80 / 154(51.9)$ & $78 / 129(60.5)$ & 2/18 (11.1) & $0 / 2(0)$ & $0 / 5(0)$ & $<0.001$ \\
\hline Bi-leaflet prolapse* & $14 / 154(9.1)$ & $14 / 129(10.9)$ & $0 / 18(0)$ & $0 / 2(0)$ & $0 / 5(0)$ & 0.394 \\
\hline Leaflet thickening $(>2 \mathrm{~mm})$ & $87 / 155(56.1)$ & $68 / 128(53.1)$ & $15 / 18(83.3)$ & $3 / 4(75)$ & $1 / 5(20)$ & 0.028 \\
\hline Leaflet calcification & $18 / 156(11.5)$ & $7 / 129(5.4)$ & $9 / 18(50.0)$ & $2 / 4(50)$ & $0 / 5(0)$ & $<0.001$ \\
\hline MAC & 29/156 (18.6) & 24/129 (18.6) & $4(22.2)$ & $0 / 4(0)$ & $1 / 5(20)$ & 0.783 \\
\hline \multicolumn{7}{|l|}{ TTE findings ${ }^{\dagger}$} \\
\hline Anterior leaflet prolapse & $63 / 155(40.6)$ & $59 / 128(46.1)$ & $4 / 18(44.4)$ & $0 / 4(0)$ & $0 / 5(0)$ & 0.016 \\
\hline Posterior leaflet prolapse & $61 / 155(39.4)$ & $60 / 128(46.9)$ & $1 / 18(5.6)$ & $0 / 4(0)$ & $0 / 5(0)$ & 0.001 \\
\hline Bi-leaflet prolapse & $22 / 155(14.2)$ & $22 / 128(17.2)$ & $0 / 18(0)$ & $0 / 4(0)$ & $0 / 5(0)$ & 0.144 \\
\hline Leaflet thickening, calcification or MAC & $45 / 155(29.0)$ & $24 / 128(18.8)$ & $17 / 18(94.4)$ & $1 / 4(25)$ & $3 / 5(60)$ & $<0.001$ \\
\hline Operation (replacement) & $38 / 156(24.4)$ & $21 / 129(16.3)$ & $15 / 18(83.3)$ & $1 / 4(25)$ & $1 / 5(20)$ & $<0.001$ \\
\hline
\end{tabular}

Data are number of patients, with percentages in parentheses. *Two patients with congenital MR were excluded based on CT analysis because segmentation of MV scallops was difficult, ${ }^{\dagger}$ One patient had no TTE examination before surgery. MAC $=$ mitral annular calcification, MR = mitral regurgitation, TTE = transthoracic echocardiography 
anterior leaflet or bi-leaflet prolapse than TTE, and higher sensitivity and lower specificity for the evaluation of nonrepairable morphology (Supplementary Table 2 in the online-only Data Supplement). These results did not change after adjusting for disease etiology. Preoperative TEE was performed in 83 patients (53.2\%). On TEE results, findings of a non-repairable MV were considered to be present in 55 patients $(66.3 \%, 35$ with anterior prolapse, 10 with bi-leaflet prolapse, and 36 with non-repairable valve morphology).

In univariate logistic regression analysis, bi-leaflet prolapse and valve morphology on CT (leaflet thickening, leaflet calcification and MAC with calcium score $>27.5$ ) were significant predictors for valve replacement; however, anterior leaflet prolapse was not a significant predictor (Table 4). Among findings of a non-repairable MV that was assessed on TTE, valve morphology was the only significant predictor. Female sex (odds ratio [OR], 3.68; 95\% CI, 1.65-
$8.26, p=0.002)$, smaller body surface area $(0 \mathrm{R}, 0.02 ; 95 \%$ CI, $0.002-0.190, p<0.001)$, and rheumatic etiology (OR, 25; 95\% CI, 6.7-93.4, $p<0.001)$ were significant clinical variables predicting valve replacement. After adjusting for clinical variables, bi-leaflet prolapse and leaflet thickening, as well as leaflet calcification (calcium score $>5.6$ ) on CT were independent factors associated with actual valve replacement. None of the TTE findings were a significant predictor after such adjustments. When the combination of CT findings of non-repairable morphology was evaluated, leaflet thickening combined with MAC was the only significant predictors, before and after adjustment. After excluding 18 patients with a rheumatic etiology, CT findings of bi-leaflet prolapse, leaflet thickening and MAC were significant predictors of valve replacement (Supplementary Table 3 in the online-only Data Supplement). When adjusting for clinical variables, CT findings of bi-leaflet prolapse, leaflet thickening, and MAC (calcium score > 17.2)

Table 4. Logistic Regression Analysis for Prediction of Actual MV Replacement

\begin{tabular}{|c|c|c|c|c|c|c|}
\hline \multirow{2}{*}{ Variables } & \multicolumn{3}{|c|}{ Unadjusted } & \multicolumn{3}{|c|}{ Adjusted for Clinical Variables } \\
\hline & OR $(95 \% \mathrm{CI})$ & $P$ & AUC & OR $(95 \% \mathrm{CI})$ & $P$ & AUC \\
\hline \multicolumn{7}{|l|}{ CT findings } \\
\hline Anterior leaflet prolapse & $0.67(0.30-1.52)$ & 0.337 & 0.542 & $1.44(0.55-3.81)$ & 0.460 & 0.842 \\
\hline Bi-leaflet prolapse & $3.58(1.14-11.00)^{*}$ & $0.026^{*}$ & $0.562^{*}$ & $8.63(2.12-33.57)^{*}$ & $0.002^{*}$ & $0.861^{*}$ \\
\hline \multicolumn{7}{|l|}{ Valve morphology } \\
\hline Leaflet thickening (leaflet thickness $>2 \mathrm{~mm}$ ) & $6.01(2.34-15.45)^{*}$ & $<0.001^{*}$ & $0.686^{*}$ & $4.14(1.39-12.40)^{*}$ & $0.011^{*}$ & $0.861^{*}$ \\
\hline \multicolumn{7}{|l|}{ Leaflet calcification } \\
\hline Presence of leaflet calcification & $6.46(2.29-18.22)^{*}$ & $<0.001^{*}$ & $0.615^{*}$ & $2.22(0.56-8.77)$ & 0.255 & 0.845 \\
\hline Leaflet calcium score $(>5.6$ ) & $11.61(3.43-39.28)^{*}$ & $<0.001^{*}$ & $0.628^{*}$ & $5.37(1.08-26.62)^{*}$ & $0.040^{*}$ & $0.845^{*}$ \\
\hline \multicolumn{7}{|l|}{ MAC } \\
\hline Presence of MAC & $2.26(0.96-5.36)$ & 0.063 & 0.568 & $1.66(0.58-4.73)$ & 0.341 & 0.849 \\
\hline MAC calcium score $(>27.5)$ & $3.29(1.33-8.15)^{*}$ & $0.010^{*}$ & $0.590^{*}$ & $2.74(0.90-8.38)$ & 0.077 & 0.854 \\
\hline \multicolumn{7}{|l|}{ Combination of morphologic findings } \\
\hline Leaflet thickening + leaflet calcification & $7.01(2.18-22.53)^{*}$ & $0.001^{*}$ & $0.597^{*}$ & $3.53(0.83-15.06)$ & 0.088 & 0.846 \\
\hline Leaflet thickening $+\mathrm{MAC}$ & $6.67(2.23-19.90)^{*}$ & $<0.001^{*}$ & $0.606^{*}$ & $5.28(1.45-19.15)^{*}$ & $0.011^{*}$ & $0.856^{*}$ \\
\hline Leaflet calcification + MAC & $3.29(0.63-17.01)$ & 0.156 & 0.527 & $0.75(0.08-6.79)$ & 0.796 & 0.841 \\
\hline $\begin{array}{l}\text { Leaflet thickening + leaflet calcification + MAC } \\
\text { calcium score }(>27.5)\end{array}$ & $4.97(0.80-30.95)$ & 0.086 & 0.531 & $2.22(0.24-20.92)$ & 0.458 & 0.842 \\
\hline Leaflet thickening + leaflet calcium score $(>5.6)$ & $10.22(2.56-40.89)^{*}$ & $0.001^{*}$ & $0.593^{*}$ & $5.22(0.93-29.39)$ & 0.061 & 0.847 \\
\hline Leaflet thickening + MAC calcium score $(>27.5)$ & $7.60(2.14-26.95)^{*}$ & $0.002^{*}$ & $0.588^{*}$ & $6.88(1.58-30.02)^{*}$ & $0.010^{*}$ & 0.849 * \\
\hline Leaflet calcium score $(>5.6)+$ MAC & $2.13(0.34-13.25)$ & 0.418 & 0.514 & $0.21(0.01-3.03)$ & 0.251 & 0.844 \\
\hline $\begin{array}{l}\text { Leaflet thickening + leaflet calcium score }(>5.6) \\
+ \text { MAC calcium score }(>27.5)\end{array}$ & $3.22(0.44-34.70)$ & 0.250 & 0.518 & $0.84(0.06-12.87)$ & 0.901 & 0.842 \\
\hline \multicolumn{7}{|l|}{ Preoperative TTE findings } \\
\hline Anterior leaflet prolapse & $0.81(0.38-1.72)$ & 0.583 & 0.525 & $1.22(0.48-3.09)$ & 0.675 & 0.838 \\
\hline Bi-leaflet prolapse & $1.18(0.43-3.28)$ & 0.746 & 0.511 & $2.05(0.65-6.44)$ & 0.219 & 0.835 \\
\hline Leaflet thickening, calcification or MAC & $5.62(2.55-12.37)^{*}$ & $<0.001^{*}$ & $0.691^{*}$ & $2.83(0.97-8.26)$ & 0.057 & 0.851 \\
\hline
\end{tabular}

*Values indicate statistical significance. $\mathrm{AUC}=$ area under curve, $\mathrm{CI}=$ confidence interval, $\mathrm{OR}=$ odds ratio 
Table 5. Comparison of CT and TTE Findings According to Presence of Recurrent MR on Follow-Up

\begin{tabular}{|c|c|c|c|}
\hline Recurrent MR & Present $(n=7)$ & Absent $(n=95)$ & $P$ \\
\hline \multicolumn{4}{|l|}{$\mathrm{CT}$} \\
\hline $\begin{array}{l}\text { Anterior leaflet } \\
\text { prolapse }\end{array}$ & $3(42.9)$ & $30(31.6)$ & 0.844 \\
\hline Bi-leaflet prolapse & $1(14.3)$ & $6(6.3)$ & 0.976 \\
\hline $\begin{array}{l}\text { Leaflet thickening } \\
\text { or calcification }\end{array}$ & $1(14.3)$ & $11(12.9)$ & 0.700 \\
\hline \multicolumn{4}{|l|}{ TTE } \\
\hline $\begin{array}{l}\text { Preoperative } \\
\text { LVEDD (mm) }\end{array}$ & $66(61-71)$ & $59(53.8-63.3)$ & $0.040^{*}$ \\
\hline $\begin{array}{l}\text { Preoperative LVEF } \\
(\%)\end{array}$ & $68(63.3-72.8)$ & $66(60-73)$ & $0.831^{*}$ \\
\hline $\begin{array}{l}\text { Postoperative } \\
\text { LVEDD (mm) }\end{array}$ & $51.5(49-68)$ & $50(46-54)$ & $0.357^{*}$ \\
\hline $\begin{array}{l}\text { Postoperative LVEF } \\
(\%)\end{array}$ & $62(57.3-4)$ & $62(57-65)$ & 0.830 * \\
\hline
\end{tabular}

Except where indicated, data are number of patients, with percentages in parentheses. *Data are medians, with 25th-75th percentile range in parentheses. LVEDD = left-ventricular enddiastolic dimension, LVEF = left-ventricular ejection fraction

remained as independent predictors.

\section{Follow-Up Clinical Outcomes}

During the mean follow-up interval of $599.8 \pm 237.7$ days, 102 patients with MV repair had available followup TTE examinations. Among these 102 patients, seven cases of recurrent MR (6.9\%) were observed on the followup TTE (Table 5). There was no significant difference in preoperative $\mathrm{CT}$ findings according to the presence of recurrent MR. Patients with recurrent MR showed a larger preoperative LV end-diastolic dimension than patients without recurrent MR $(p=0.040)$. Neither the type of surgical technique (ring annuloplasty only versus ring annuloplasty combined with other techniques) nor the etiology of MV disease was significantly different between the groups according to the presence of recurrent MR ( $p$ $>0.05$ ). Only one patient underwent re-operation (MV replacement) due to recurrent MR during follow-up.

\section{DISCUSSION}

Our study demonstrates that cardiac CT can accurately detect MV prolapse in patients with severe MR and can predict a non-repairable MV. Among the findings for a nonrepairable MV, bi-leaflet prolapse and valve morphology defined as leaflet thickening, calcification, or MAC on CT were important determinants of a valve replacement.

Among the MV findings that were considered as unsuitable for repair in our study, the anterior leaflet was not a critical component when selecting MV repair. Valve morphology was the most important predictor of valve replacement with the highest area under the curve on the logistic regression analysis. We speculate that this result may be because the surgeons at our institution have extensive experience in MV surgery and achieved a successful repair in cases of anterior prolapse (35). This result is consistent with findings from a previous study where an almost $100 \%$ repair rate was achieved for anterior or bi-leaflet prolapse in a high-volume reference center (6).

Valve leaflet thickening and/or calcification can accompany leaflet restriction and is mostly seen in rheumatic valve disease, which favors MV replacement rather than repair. However, non-repairable leaflet morphology is not a pathognomonic finding for rheumatic heart disease, and non-rheumatic MV disease, such as myxomatous degeneration, can lead to leaflet thickening or calcification, which leads to unfavorable outcomes after MV repair is attempted. In addition, MAC can be seen in degenerative MV disease and sometimes results in MR or mitral stenosis and is considered to be less suitable for conventional MV repair due to poor postoperative outcomes (36-39). In our study, after exclusion of patients with a rheumatic etiology, valve morphology, such as leaflet thickening and the presence of $M A C$, remained an independent predictor of valve replacement, indicating the importance of valve morphology when planning MV surgery. Accordingly, careful preoperative evaluation of the valve morphology is crucial for both planning of surgery and predicting postoperative outcomes.

According to the current guidelines, a well-established indication of cardiac CT for valvular heart disease includes preoperative coronary artery evaluation (40-43). Indeed, most of our study population underwent cardiac CT for the main purpose of coronary artery evaluation before MV surgery. However, the excellent spatial resolution of cardiac CT is a great benefit in the evaluation of anatomical structures and geometry despite the inferior temporal resolution compared to other imaging modalities. A few previous studies using cardiac CT in MV disease focused on the evaluation of the diagnostic performance of cardiac CT for the detection of MV prolapse in degenerative MV disease, with sensitivity in the range of $84.6-96.2 \%$ and specificity in the range of $93.2-100 \%$ per patient (23-26). 
Our study found a higher sensitivity (99.1\%) but lower specificity $(81.4 \%)$ than the previous studies. This may be explained by differences in patient characteristics such as the disease etiology and type of CT scanner used.

Besides the detection and localization of MV prolapse, cardiac CT can be a useful modality for the morphologic evaluation of MV, as shown in our study. Although TTE can provide information regarding valve morphology, CT comprehensively evaluates each of the non-repairable MV findings, especially when TTE cannot give sufficient information. For example, leaflet calcification and MAC cannot only be visually assessed, but also can be measured quantitatively using Agatston scoring. In our study, CT showed higher sensitivity and specificity for the evaluation of the location of MV prolapse, and higher sensitivity and lower specificity for the evaluation of non-repairable morphology, than TTE. In particular, cardiac CT may be an effective and useful tool to evaluate MAC, both in the visualization of its extent and location and quantification by calcium scoring $(44,45)$. Furthermore, cardiac CT has been used for the geometric assessment of the MV apparatus and $\mathrm{LV}$ remodeling to help determine the mechanism of functional MR $(27,46)$. Other applications of cardiac CT for the MV include informing the decision on the approach in MV surgery (minimally invasive surgery or sternotomy) (47) and pre-procedural planning of transcatheter MV implantation (48-51). CT can be an alternative imaging technique for MV evaluation in patients with a suboptimal TTE window and those that have a contraindication to cardiac magnetic resonance imaging. Based on the results of our study, we expect that the application of cardiac CT can be extended to preoperative planning before MV surgery.

Postoperative adverse outcomes include recurrent MR, which is associated with subsequent re-operation and cardiac death (11, 17-19). According to our study results, recurrent MR seems to be associated with LV geometry rather than the extent of MV prolapse or valve morphology. In our study, the LV end-diastolic dimension was larger in patients with recurrent MR in preoperative TTE, which was consistent with a previous study finding that recurrent MR in repair of degenerative MR was associated with adverse LV remodeling (19). Nevertheless, the influence of MV morphology and extent of MV prolapse should not be overlooked in the planning of MV surgery.

Our study has several limitations. First, the rate of performing MV repair rather than replacement and successful postoperative repair rate depends on the experience of the surgeon and/or valve team $(5,6)$. Our study result may not be generalized to institutions with less experienced surgeons and/or small patient volumes. Second, a selection bias may exist, because we only included patients who underwent a preoperative cardiac CT scan before MV surgery due to severe MR and did not include all patients who received MV surgery. Third, we did not compare the diagnostic performance of TEE, considering a potential selection bias because TEE was performed in only 83 patients (53.2\%) of our study population. Rather, we described the brief results of TEE findings for a non-repairable valve. Finally, the potential hazard of radiation exposure from CT scanning should not be overlooked. Although we applied dose reduction strategies, such as automatic tube potential selection and concurrent automatic exposure control of tube current, we used retrospective ECG-gating without ECG-based tube current modulation, which may lead to an increase in the radiation dose. Further attempts to modify imaging acquisition protocols via a single-beat prospective ECG-gated imaging acquisition, using a wide detector-row scanner or robust iterative reconstruction techniques, will be more appropriate in reducing the radiation dose in the CT evaluation of patients with valvular heart disease.

In conclusion, cardiac $\mathrm{CT}$ can have high diagnostic performance in detecting MV prolapse and predicting MV replacement before surgery. Among the CT findings, bileaflet prolapse and valve morphology features, such as leaflet thickening, calcification, or MAC, are the most important predictors of a non-repairable MV.

\section{Supplementary Materials}

The online-only Data Supplement is available with this article at https://doi.org/10.3348/kjr.2018.0350.

\section{Conflicts of Interest}

The authors have no potential conflicts of interest to disclose.

\section{Acknowledgments}

We would like to thank Kyunghwa Han (statistical expert, Department of Radiology, Yonsei University College of Medicine) for her help in revising the manuscript.

ORCID iDs

Young Jin Kim

https://orcid.org/0000-0002-6235-6550 
Young Joo Suh

https://orcid.org/0000-0002-2078-5832

Sak Lee

https://orcid.org/0000-0001-6130-2342

\section{REFERENCES}

1. McNeely CA, Vassileva CM. Long-term outcomes of mitral valve repair versus replacement for degenerative disease: a systematic review. Curr Cardiol Rev 2015;11:157-162

2. Shuhaiber J, Anderson RJ. Meta-analysis of clinical outcomes following surgical mitral valve repair or replacement. Eur J Cardiothorac Surg 2007;31:267-275

3. Lazam S, Vanoverschelde JL, Tribouilloy C, Grigioni F, Suri $\mathrm{RM}$, Avierinos JF, et al. Twenty-year outcome after mitral repair versus replacement for severe degenerative mitral regurgitation: analysis of a large, prospective, multicenter, international registry. Circulation 2017;135:410-422

4. Gammie JS, Sheng S, Griffith BP, Peterson ED, Rankin JS, $O^{\prime} B$ rien $S M$, et al. Trends in mitral valve surgery in the United States: results from the society of thoracic surgeons adult cardiac surgery database. Ann Thorac Surg 2009;87:14311437; discussion 1437-1439

5. Bolling SF, Li S, O'Brien SM, Brennan JM, Prager RL, Gammie JS. Predictors of mitral valve repair: clinical and surgeon factors. Ann Thorac Surg 2010;90:1904-1911; discussion 1912

6. Castillo JG, Anyanwu AC, Fuster V, Adams DH. A near 100\% repair rate for mitral valve prolapse is achievable in a reference center: implications for future guidelines. $J$ Thorac Cardiovasc Surg 2012;144:308-312

7. David TE, Ivanov J, Armstrong S, Christie D, Rakowski H. A comparison of outcomes of mitral valve repair for degenerative disease with posterior, anterior, and bileaflet prolapse. J Thorac Cardiovasc Surg 2005;130:1242-1249

8. Mihaljevic T, Jarrett CM, Gillinov AM, Williams SJ, DeVilliers PA, Stewart WJ, et al. Robotic repair of posterior mitral valve prolapse versus conventional approaches: potential realized. J Thorac Cardiovasc Surg 2011;141:72-80. e1-e4

9. David TE. Durability of mitral valve repair for mitral regurgitation due to degenerative mitral valve disease. Ann Cardiothorac Surg 2015;4:417-421

10. Gillinov AM, Cosgrove DM, Blackstone EH, Diaz R, Arnold $\mathrm{JH}$, Lytle BW, et al. Durability of mitral valve repair for degenerative disease. J Thorac Cardiovasc Surg 1998;116:734743

11. David TE, Armstrong S, McCrindle BW, Manlhiot C. Late outcomes of mitral valve repair for mitral regurgitation due to degenerative disease. Circulation 2013;127:1485-1492

12. Oliveira JM, Antunes MJ. Mitral valve repair: better than replacement. Heart 2006;92:275-281

13. Fusini L, Ghulam Ali S, Tamborini G, Muratori M, Gripari P, Maffessanti $F$, et al. Prevalence of calcification of the mitral valve annulus in patients undergoing surgical repair of mitral valve prolapse. Am J Cardiol 2014;113:1867-1873

14. Okada Y. Surgical management of mitral annular calcification. Gen Thorac Cardiovasc Surg 2013;61:619-625

15. Carpentier AF, Pellerin M, Fuzellier JF, Relland JY. Extensive calcification of the mitral valve anulus: pathology and surgical management. J Thorac Cardiovasc Surg 1996;111:718729; discussion 729-730

16. Uchimuro T, Fukui T, Shimizu A, Takanashi S. Mitral valve surgery in patients with severe mitral annular calcification. Ann Thorac Surg 2016;101:889-895

17. Gillinov AM, Cosgrove DM, Lytle BW, Taylor PC, Stewart RW, McCarthy PM, et al. Reoperation for failure of mitral valve repair. J Thorac Cardiovasc Surg 1997;113:467-473; discussion 473-475

18. DiBardino DJ, ElBardissi AW, McClure RS, Razo-Vasquez OA, Kelly NE, Cohn LH. Four decades of experience with mitral valve repair: analysis of differential indications, technical evolution, and long-term outcome. J Thorac Cardiovasc Surg 2010;139:76-83; discussion 83-84

19. Suri RM, Clavel MA, Schaff HV, Michelena HI, Huebner M, Nishimura RA, et al. Effect of recurrent mitral regurgitation following degenerative mitral valve repair: long-term analysis of competing outcomes. J Am Coll Cardiol 2016;67:488-498

20. Northrup WF 3rd, DuBois KA, Kshettry VR. Morbidity and mortality of a failed attempt at mitral valve repair converted to replacement at the same operation. J Heart Valve Dis 2003;12:700-706

21. Ben Zekry S, Nagueh SF, Little SH, Quinones MA, McCulloch $M L$, Karanbir $S$, et al. Comparative accuracy of two- and three-dimensional transthoracic and transesophageal echocardiography in identifying mitral valve pathology in patients undergoing mitral valve repair: initial observations. $J$ Am Soc Echocardiogr 2011;24:1079-1085

22. Kim JH, Kim EY, Jin GY, Choi JB. A review of the use of cardiac computed tomography for evaluating the mitral valve before and after mitral valve repair. Korean J Radiol 2017;18:773-785

23. Ghosh N, Al-Shehri H, Chan K, Mesana T, Chan V, Chen L, et al. Characterization of mitral valve prolapse with cardiac computed tomography: comparison to echocardiographic and intraoperative findings. Int J Cardiovasc Imaging 2012;28:855-863

24. Feuchtner GM, Alkadhi H, Karlo C, Sarwar A, Meier A, Dichtl W, et al. Cardiac CT angiography for the diagnosis of mitral valve prolapse: comparison with echocardiography1. Radiology 2010;254:374-383

25. Smith T, Gurudevan S, Cheng V, Trento A, Derobertis M, Thomson $L$, et al. Assessment of the morphological features of degenerative mitral valve disease using 64-slice multi detector computed tomography. J Cardiovasc Comput Tomogr 2012;6:415-421

26. Shah RG, Novaro GM, Blandon RJ, Wilkinson L, Asher CR, Kirsch J. Mitral valve prolapse: evaluation with ECG-gated cardiac CT angiography. AJR Am J Roentgenol 2010;194:579-584 
27. Delgado V, Tops LF, Schuijf JD, de Roos A, Brugada J, Schalij $M J$, et al. Assessment of mitral valve anatomy and geometry with multislice computed tomography. JACC CardiovasC Imaging 2009;2:556-565

28. Ng C, Nesser J, Punzengruber J, Pandian NG, Khandheria B, Hartl $\mathrm{P}$, et al. Modern mitral valve repair: echocardiographic interpretations and surgical strategies. New York, NY: Springer Verlag, 2003:29-87

29. Carpentier A. Cardiac valve surgery--the "French correction". J Thorac Cardiovasc Surg 1983;86:323-337

30. Agatston AS, Janowitz WR, Hildner FJ, Zusmer NR, Viamonte M Jr, Detrano R. Quantification of coronary artery calcium using ultrafast computed tomography. J Am Coll Cardiol 1990;15:827-832

31. Silaschi M, Chaubey S, Aldalati 0, Khan H, Uzzaman MM, Singh $M$, et al. Is mitral valve repair superior to mitral valve replacement in elderly patients? Comparison of short- and long-term outcomes in a propensity-matched cohort. J Am Heart Assoc 2016;5. pii: e003605

32. Lang RM, Badano LP, Mor-Avi V, Afilalo J, Armstrong A, Ernande $L$, et al. Recommendations for cardiac chamber quantification by echocardiography in adults: an update from the American Society of Echocardiography and the European Association of Cardiovascular Imaging. Eur Heart J Cardiovasc Imaging 2015;16:233-270

33. Quinones MA, Waggoner AD, Reduto LA, Nelson JG, Young JB, Winters WL Jr, et al. A new, simplified and accurate method for determining ejection fraction with two-dimensional echocardiography. Circulation 1981;64:744-753

34. Zoghbi WA, Enriquez-Sarano M, Foster E, Grayburn PA, Kraft $C D$, Levine RA, et al. Recommendations for evaluation of the severity of native valvular regurgitation with two-dimensional and doppler echocardiography. J Am Soc Echocardiogr 2003; 16:777-802

35. Kim JH, Lee SH, Joo HC, Youn YN, Yoo KJ, Chang BC, et al. Effect of recurrent mitral regurgitation after mitral valve repair in patients with degenerative mitral regurgitation. Circ J 2017;82:93-101

36. Labovitz AJ, Nelson JG, Windhorst DM, Kennedy HL, Williams $\mathrm{GA}$. Frequency of mitral valve dysfunction from mitral anular calcium as detected by doppler echocardiography. $\mathrm{Am} \mathrm{J}$ Cardiol 1985;55:133-137

37. Movahed MR, Saito Y, Ahmadi-Kashani M, Ebrahimi R. Mitral annulus calcification is associated with valvular and cardiac structural abnormalities. Cardiovasc Ultrasound 2007;5:14

38. Muddassir SM, Pressman GS. Mitral annular calcification as a cause of mitral valve gradients. Int J Cardiol 2007;123:58-62

39. Nestico PF, Depace NL, Morganroth J, Kotler MN, Ross J. Mitral annular calcification: clinical, pathophysiology, and echocardiographic review. Am Heart J 1984;107:989-996

40. Kim YJ, Yong HS, Kim SM, Kim JA, Yang DH, Hong YJ, et al. Korean guidelines for the appropriate use of cardiac CT.
Korean J Radiol 2015;16:251-285

41. Pontone G, Andreini D, Bertella E, Cortinovis S, Mushtaq $\mathrm{S}$, Foti $\mathrm{C}$, et al. Pre-operative CT coronary angiography in patients with mitral valve prolapse referred for surgical repair: comparison of accuracy, radiation dose and cost versus invasive coronary angiography. Int J Cardiol 2013;167:28892894

42. Morris MF, Suri RM, Akhtar NJ, Young PM, Gruden JF, Burkhart $H M$, et al. Computed tomography as an alternative to catheter angiography prior to robotic mitral valve repair. Ann Thorac Surg 2013;95:1354-1359

43. Nishimura RA, Otto CM, Bonow RO, Carabello BA, Erwin JP 3rd, Guyton RA, et al. 2014 AHA/ACC guideline for the management of patients with valvular heart disease: a report of the American College of Cardiology/American Heart Association Task Force on practice guidelines. Circulation 2014;129:e521-e643

44. Higgins J, Mayo J, Skarsgard P. Cardiac computed tomography facilitates operative planning in patients with mitral calcification. Ann Thorac Surg 2013;95:e9-e11

45. Hamirani YS, Nasir K, Blumenthal RS, Takasu J, Shavelle $D$, Kronmal R, et al. Relation of mitral annular calcium and coronary calcium (from the Multi-Ethnic Study of Atherosclerosis [MESA]). Am J Cardiol 2011;107:1291-1294

46. Killeen RP, Arnous S, Martos R, Abbara S, Quinn M, Dodd JD. Chronic mitral regurgitation detected on cardiac MDCT: differentiation between functional and valvular aetiologies. Eur Radiol 2010;20:1886-1895

47. Moodley S, Schoenhagen P, Gillinov AM, Mihaljevic T, Flamm SD, Griffin BP, et al. Preoperative multidetector computed tomograpy angiography for planning of minimally invasive robotic mitral valve surgery: impact on decision making. $J$ Thorac Cardiovasc Surg 2013;146:262-268. e1

48. Blanke P, Dvir D, Cheung A, Ye J, Levine RA, Precious B, et al. A simplified $D$-shaped model of the mitral annulus to facilitate CT-based sizing before transcatheter mitral valve implantation. J Cardiovasc Comput Tomogr 2014;8:459-467

49. Blanke P, Naoum C, Webb J, Dvir D, Hahn RT, Grayburn P, et al. Multimodality imaging in the context of transcatheter mitral valve replacement: establishing consensus among modalities and disciplines. JACC Cardiovasc Imaging 2015;8:1191-1208

50. Mak GJ, Blanke P, Ong K, Naoum C, Thompson CR, Webb JG, et al. Three-dimensional echocardiography compared with computed tomography to determine mitral annulus size before transcatheter mitral valve implantation. Circ Cardiovasc Imaging 2016;9. pii: e004176

51. Naoum C, Leipsic J, Cheung A, Ye J, Bilbey N, Mak G, et al. Mitral annular dimensions and geometry in patients with functional mitral regurgitation and mitral valve prolapse: implications for transcatheter mitral valve implantation. JACC Cardiovasc Imaging 2016;9:269-280 